\title{
Risk Factors for Physical Inactivity Among Children With and Without Asthma Living in Peri-Urban Communities of Lima, Peru
}

\section{Sathvik Namburar, William Checkley, Oscar Flores-Flores, Karina M. Romero, Katherine Tomaino Fraser, Nadia N. Hansel, and Suzanne L. Pollard, GASP Study Investigators}

\begin{abstract}
Background: The authors sought to examine physical activity patterns among children with and without asthma in 2 peri-urban communities in Lima, Peru, to identify socioeconomic and demographic risk factors for physical inactivity and examine the relationship between asthma and physical activity. Methods: The authors measured mean steps per day in 114 children (49 with asthma and 65 without) using pedometers worn over a 1-week period. They also used the 3 -day physical activity recall to determine the most common activities carried out by children. Results: The authors found that $84.2 \%$ of the children did not meet the daily international physical activity recommendations. Girls took significantly fewer mean steps per day as compared with boys (2258 fewer steps, 95\% confidence interval, 1042-3474), but no other factors, including asthma status, showed significant differences in the mean daily steps. Mean daily steps were positively associated with higher socioeconomic status among girls, and current asthma had a larger inverse effect on daily steps in boys when compared with girls. Conclusion: Physical activity levels were below recommended guidelines in all children. There is a need for policy and neighborhood-level interventions to address low physical activity levels among Peruvian youth. Special focus should be given to increasing the physical activity levels in girls.
\end{abstract}

Keywords: gender, epidemiology, South America

Physical inactivity is a worldwide epidemic and is one of the leading risk factors for premature death worldwide. ${ }^{1}$ An estimated $23 \%$ of adults and $81 \%$ of adolescents do not currently meet the World Health Organization's recommendations for regular exercise of 60 minutes of daily exercise for adolescents and 150 minutes of weekly exercise for adults. ${ }^{1}$ A lack of physical activity is an important and well-recognized risk factor for noncommunicable diseases across the lifespan, and regular activity is a critical component of promoting and maintaining mental and physical health and well-being. For this reason, World Health Organization member states have pledged to reduce physical inactivity by $10 \%$ by 2025 , and the promotion of physical activity and sport is a key element of the United Nations 2030 Agenda for Sustainable Development to ensure healthy lives and promote well-being for all. ${ }^{2}$

The evidence suggests that physical inactivity may be an important modifiable risk factor for asthma, influencing its development, course, and severity. ${ }^{3-5}$ Asthma is the most common chronic disease in childhood and, similar to physical inactivity, is strongly associated with living in an urban environment. ${ }^{6}$ Physical activity may influence the severity and progression of asthma by reducing inflammation; at the same time, physical activity may serve as a mediator for the relationship between asthma and obesity. ${ }^{7-9}$ Individuals with asthma may also be less

\footnotetext{
Namburar is with the Department of Public Health Studies, Johns Hopkins University, Baltimore, MD, USA. Checkley, Romero, Hansel, and Pollard are with the Division of Pulmonary and Critical Care, School of Medicine, Johns Hopkins University, Baltimore, MD, USA. Checkley, Fraser, and Pollard are with the Department of International Health, Bloomberg School of Public Health, Johns Hopkins University, Baltimore, MD, USA. Flores-Flores is with the Centro de Investigación del Envejecimiento (CIEN), Facultad de Medicina Humana, Universidad de San Martin de Porres, Lima, Peru; the Asociación Benéfica PRISMA, Lima, Perú; and the Facultad de Ciencias de la Salud, Universidad Cientifica del Sur, Lima, Peru. Pollard (spollard@jhu.edu) is corresponding author.
}

physically active due to real or perceived limitations in their ability to engage in exercise. Given the paucity of research regarding physical activity patterns among youth in low- and middle-income countries, we conducted a study to evaluate physical activity in children with and without asthma in Peru.

\section{Methods}

\section{Study Setting}

We enrolled children between the ages of 9 and 19 living in one of 2 communities, Pampas de San Juan and Villa El Salvador, located in the southern cone of Lima, Peru. Both districts have seen significant population growth in recent decades, largely due to an influx of migrants from the country's highland regions. This demographic shift is representative of Peru as a whole, where the percentage of individuals living in urban areas has increased from $47 \%$ to $78 \%$ between 1960 and $2018 .{ }^{10}$ In 2011, our prior research demonstrated that, among adolescents 13-15 years of age in Pampas de San Juan, 22\% experienced lifetime wheeze, $12 \%$ currently had asthma symptoms, and $13 \%$ had a physician's diagnosis of asthma. ${ }^{11}$ This study was approved by the institutional review boards at the Johns Hopkins University School of Medicine, Baltimore, and the Asociación Benéfica PRISMA in Lima, Peru, and informed consent was obtained from all participants.

\section{Study Design}

This study was ancillary to an unmatched case-control study carried out in 506 children, 9-19 years of age, with current asthma and 671 children without asthma. We enrolled a random, sexstratified subset of 114 children, 49 with asthma and 65 without asthma. Children having had ocular, thoracic, or abdominal surgery in the last 3 months were excluded from the parent study, as were children who had been hospitalized for cardiac reasons in the last 
3 months, had tuberculosis or a chronic respiratory condition other than asthma, were receiving treatment for tuberculosis, or were pregnant. Additional details regarding recruitment for the parent study have been published elsewhere. ${ }^{12,13}$ This study had 3 objectives. The first objective was to characterize physical activity patterns among youth, using both qualitative (questionnaire based) and quantitative (motion tracking) methods. The second objective was to identify sociodemographic risk factors for physical inactivity. Finally, we sought to examine the relationship between current asthma and physical activity in Peruvian children and adolescents in these communities. We hypothesized that children with asthma would be less physically active than children without asthma and that the majority of children would have physical activity levels below those recommended by international guidelines. ${ }^{1}$

\section{Definitions}

We defined asthma as having had symptoms of asthma or medication use for asthma in the previous 12 months. The data collection for this ancillary study was carried out between November 2013 and November 2014.

\section{Baseline Questionnaire}

We administered a baseline questionnaire that included sociodemographic information, the family history of asthma, medication use, health care utilization, and socioeconomic status.

\section{3-Day Physical Activity Recall}

The 3-day physical activity recall (3DPAR) is a validated instrument designed to prompt children to recall their daily activities, as well as their intensity, in 30-minute increments over the previous 3 days. ${ }^{14,15}$ The 3DPAR has been validated in pediatric populations and distinguishes between sedentary and nonsedentary physical activities. ${ }^{15}$ The questionnaire can also be used to calculate metabolic equivalents, a measure of energy expended, although we did not collect the relevant data to do so in this study. ${ }^{16,17} \mathrm{We}$ administered the 3DPAR once to each child at the end of the week of pedometer use to capture the last 3 days of the activity period.

\section{Pedometers}

We used the HJ-720ITC Pocket Pedometer (Omron Healthcare, Inc, Bannockburn, IL) to measure the number of steps taken by children per day over 7 full consecutive days. The HJ-720ITC allows for the direct download of data to a computer, thus avoiding the need for children to remember to record their total steps at the end of each day. ${ }^{18}$ This pedometer also has a sensor to detect whether it was worn during each hour of the day. We asked children to complete diaries in which they recorded whether they wore the pedometer on that day. Using a combination of the pedometer report and self-report, we removed days from the analysis in which the pedometer was worn by the child for less than 10 hours in a single day.

\section{Biostatistical Methods}

We used both single variable and multivariable linear and logistic regressions to determine the unadjusted and adjusted associations between physical activity (mean steps per day) and asthma status, as well as other factors, including sex, age, SES, body mass index (BMI), and study community. We generated a composite score for SES using principal component analysis techniques. Under this method, a higher score indicated a lower SES. This score was based on a series of variables related to the SES of participant households, such as the presence or absence of common household appliances, the size of the household, and years of parental education. Additional details about these methods can be found elsewhere. ${ }^{12,13} \mathrm{We}$ also calculated the frequencies of daily activities, which were reported in 30-minute increments over the 3-day period. Each activity was also classified into sedentary versus nonsedentary based on whether the child was seated while doing the activity, and we calculated the number of minutes per day that the child was engaged in activities in each of these categories. This analysis was carried out by counting each 30-minute increment that a child reported a certain activity, adding up the total number of 30-minute increments that the children performed each activity and dividing each activity's tally by the total number of data points. We also calculated the percentage of time the children were engaged in each of the reported activities and conducted comparisons of daily activities stratified by asthma status. All analyses were carried out using R (www.r-project.org) and Stata (version 15; StataCorp, College Station, TX).

\section{Results}

\section{Participant Characteristics}

Among 114 children included in this analysis, 49 had asthma and 65 did not have asthma. There were no differences in age, community of residence, or the season in which children participated in the study between children with and without asthma (Table 1). Furthermore, there were no significant differences in measures of SES or BMI between children with and without asthma.

\section{Patterns of Physical Activity}

Overall, the children took an average number of 8102 steps per day $(\mathrm{SD}=3440)$, with $84.3 \%$ of children taking fewer than 11,000 daily steps per day. ${ }^{19,20}$ The 3DPAR data also demonstrated that children spent the majority of their time ( $81.5 \%$ of time on a typical day) engaged in sedentary activities, with the most common activities for all groups studied being sleeping, watching television, eating, and studying and/or sitting in class.

\section{Risk Factors of Physical Inactivity}

In Figure 1, we display crude associations between various risk factors and mean daily steps. We conducted unadjusted and adjusted linear regression analyses examining the associations between mean steps per day and age, sex, and community of residence (Table 2). In both the crude and adjusted analyses, the only factor significantly associated with mean daily steps was sex. In the adjusted analyses, girls took an average of 2258 fewer steps per day compared with boys (95\% confidence interval [CI], 10423474). In Figure 2, we display the empirical cumulative distribution functions of mean daily steps per day for girls versus boys. Age, community of residence, and BMI were not significantly associated with mean steps per day.

The results of adjusted analyses stratified by sex demonstrate that higher socioeconomic status is positively associated with mean 
Table 1 A Comparison of Demographic Values Among Children With Asthma and Children Without Asthma

\begin{tabular}{|c|c|c|c|}
\hline & Asthma & No asthma & \\
\hline Sample size & 49 & 65 & $P$ value \\
\hline \multicolumn{4}{|l|}{ Demographics } \\
\hline Number of boys, $\%$ & $22(44.9)$ & $30(46.2)$ & .89 \\
\hline Age in years, mean $(\mathrm{SD})$ & $12.5(2.10)$ & $13.0(2.51)$ & .22 \\
\hline Lives in Pampas de San Juan, n (\%) & $30(61.2)$ & $48(73.9)$ & .15 \\
\hline \multicolumn{4}{|l|}{ Anthropometry } \\
\hline Average body mass index in $\mathrm{kg} / \mathrm{m}^{2}$ (SD) & $21.8(4.38)$ & $22.1(4.07)$ & .72 \\
\hline \multicolumn{4}{|l|}{ Socioeconomics, $\mathrm{n}(\%)$} \\
\hline Maternal education $\geq 6 \mathrm{y}, \mathrm{n}(\%)$ & $65(92.9)$ & $55(93.2)$ & .94 \\
\hline 6 or more household members, $\mathrm{n}(\%)$ & $18(39.1)$ & $28(45.2)$ & .53 \\
\hline \multicolumn{4}{|l|}{ Smoking } \\
\hline Has ever smoked & $2(4.35)$ & $4(6.45)$ & .64 \\
\hline Lives with a current smoker & $3(7.50)$ & $8(13.8)$ & .33 \\
\hline \multicolumn{4}{|l|}{ Season of data collection } \\
\hline Fall-winter (April-September), n (\%) & $19(38.8)$ & $17(26.2)$ & .15 \\
\hline Spring (October-March), n (\%) & $30(61.2)$ & 48 (73.9) & - \\
\hline
\end{tabular}
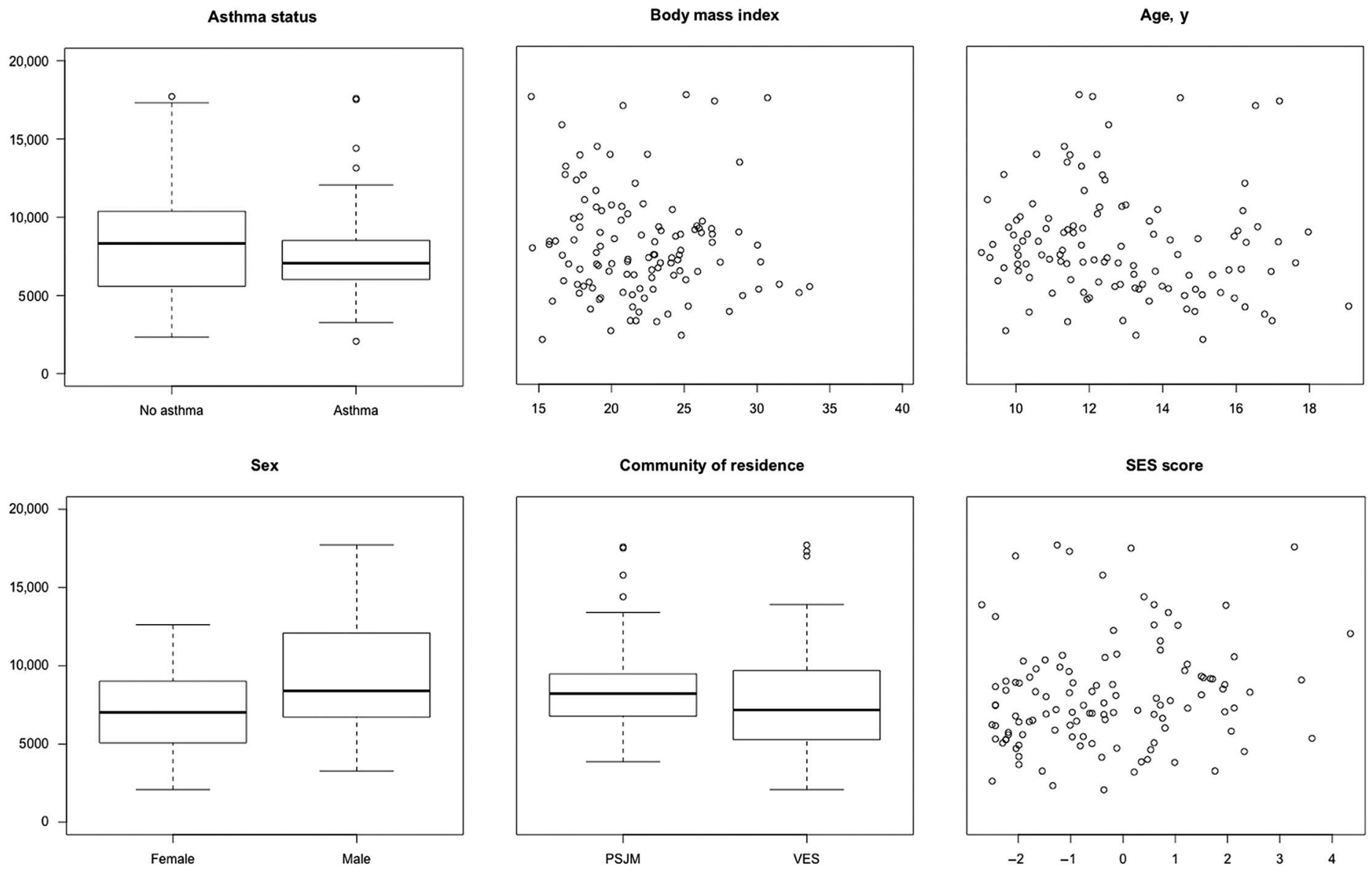

Figure 1 - Side-by-side boxplots and scatterplots displaying associations of key risk factors with mean daily steps. PSJM indicates Pampas de San Juan; VES, Villa El Salvador. 
Table 2 Crude and Adjusted Associations of Mean Steps Per Day With Current Asthma and Risk Factors

\begin{tabular}{|c|c|c|c|c|}
\hline & Unadjusted $(\beta, 95 \% \mathrm{Cl})$ & $P$ value & Adjusted $(\beta, 95 \% \mathrm{Cl})$ & $P$ value \\
\hline Current asthma & $-759.0(-2046.5$ to 528.49$)$ & .25 & $-995.9(-2221.5$ to 229.8$)$ & .11 \\
\hline Age (per 10 y) & $-162.04(-434.51$ to 110.23$)$ & .24 & $-91.18(-371.0$ to 188.6$)$ & .52 \\
\hline Sex (female is reference) & $2366.0(1157.1$ to 3574.9$)$ & $<.001$ & 2258.0 (1041.7 to 3474.4$)$ & $<.001$ \\
\hline BMI, per $10 \mathrm{~kg} / \mathrm{m}^{3}$ & $-666.76(-219.89$ to 86.543$)$ & .39 & $-242.2(-1835.2$ to 1350.6$)$ & .76 \\
\hline Location (Pampas de San Juan is reference) & $-1113.8(-2477.5$ to 249.88$)$ & .11 & $-798.4(-2251.5$ to 654.66$)$ & .28 \\
\hline SES score & $357.58(-38.857$ to 754.025$)$ & .08 & $253.1(-170.6$ to 676.8$)$ & .24 \\
\hline
\end{tabular}

Abbreviations: BMI, body mass index; CI, confidence interval.

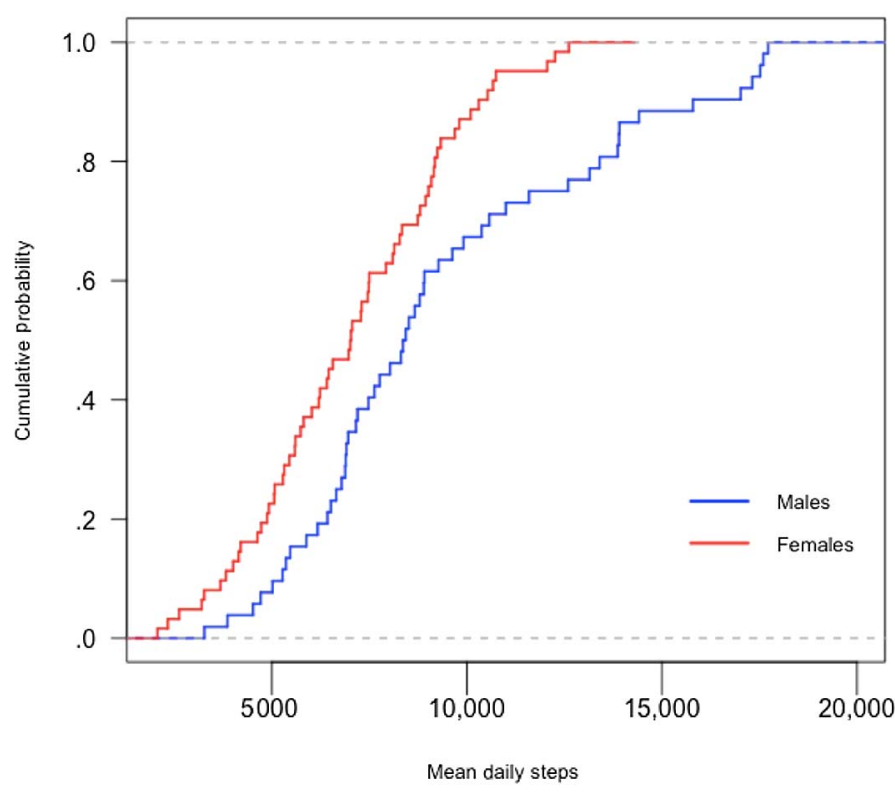

Figure 2 - Cumulative distribution function of mean daily steps among male and female children.

daily steps among girls, but not among boys (Table 3). The magnitude of the association between current asthma and mean daily steps was 15 times larger among boys, and this association approached statistical significance in the latter group (Table 3).

\section{Physical Activity and Asthma Status}

We compared mean daily steps among children with and without asthma (Table 2). The results of the adjusted analyses showed that children with asthma took an average of 995.9 fewer steps per day than children without asthma (95\% CI, -2221.5 to 229.8); however, this difference was not statistically significant $(P=.11)$.

We display the 3 most common activities for each 30-minute period and the relative frequency of activities overall (Table 4). The 5 most common activities for children both with and without asthma were sleeping, watching television/movies, eating, studying/doing homework, and writing/taking notes in class. There was no statistically significant difference in sedentariness between the asthma and control groups, with children with asthma spending an average of $16.6 \%$ of each day engaged in nonsedentary activity compared with $15.7 \%$ among children without asthma $(P=.14)$.

\section{Discussion}

In our cohort of 114 children in a peri-urban community in Lima, Peru, we found that physical activity levels were far lower than what is recommended by international and national guidelines. ${ }^{1-2}$ The data from the 3-day recalls demonstrated that both groups of children spent the majority of their time engaged in sedentary activities, including watching television, schoolwork, and Internet or video games. When comparing the data based on sociodemographic factors, girls took fewer steps than boys, even after adjusting for confounders, while other variables, such as BMI, age, and community of residence, did not significantly impact the number of steps taken per day. We found that higher SES was associated with higher mean daily steps among girls but not boys. We also found that the magnitude of the inverse association of current asthma with the mean daily steps was 15 times higher in boys as compared with girls. Finally, while we did not find differences in physical activity, as measured by the mean steps per day, between children with and without asthma, there was a trend whereby children with asthma took fewer steps per day compared with children without asthma.

Overall, children had lower levels of physical activity than the international recommendation of 11,000 to 16,500 steps per day for children and adolescents, ${ }^{19,20}$ and children spent most of their days engaged in sedentary activities. Across many settings in high-income countries and low- and middle-income countries alike, it has been shown that children living in urban and periurban environments live a more sedentary lifestyle due to a variety of factors. ${ }^{21}$ Physical activity in children living in urban communities is often severely limited by the built and social environments, which may be less conducive to outdoor play and other activities. Increased exposures to crime and traffic-related hazards in such environments also make children less likely to engage in outdoor physical activity. ${ }^{22}$ Consequently, these children are at an increased risk of developing noncommunicable diseases throughout the lifespan. As the number of children growing up in cities rapidly increases in low- and middle-income countries, it will be increasingly important for strategies and policies to address these factors and recognize the additional risks from sedentariness experienced by children living in urban environments.

Sex differences in physical activity levels among children have been documented in many diverse settings, including Australia, Japan, and Brazil. ${ }^{23-25}$ For example, in a study of 691 Japanese children, Ishii et $\mathrm{al}^{25}$ found that boys had significantly higher physical activity levels, as measured in metabolic equivalents, when compared with girls. In a study of the recess activities of 407 French children in 2014, Baquet et $\mathrm{al}^{26}$ found that girls engaged in significantly fewer vigorous recreational activities 
Table 3 Stratified Analyses by Sex Showing Adjusted Associations of Mean Steps Per Day With Current Asthma and Risk Factors

\begin{tabular}{|c|c|c|c|c|}
\hline & Boys $(\beta, 95 \% \mathrm{Cl})$ & $P$ value & Girls $(\beta, 95 \% \mathrm{Cl})$ & $P$ value \\
\hline Current asthma & $-2210.1(-4629.7$ to 209.6$)$ & .07 & $-145.5(-1426.0$ to 1135.0$)$ & .82 \\
\hline Age (per 10 y) & $-116.8(-690.8$ to 457.3$)$ & .68 & $-92.6(-380.1$ to 194.9$)$ & .52 \\
\hline BMI, per $10 \mathrm{~kg} / \mathrm{m}^{3}$ & $-78.4(-425.2$ to 268.3$)$ & .65 & $-34.5(-189.2$ to 120.2$)$ & .66 \\
\hline Location (Pampas de San Juan is reference) & $-2120.9(-4980.0$ to 738.1$)$ & .14 & $-236.8(-1766.2$ to 1292.6$)$ & .76 \\
\hline SES score & $-129.7(-952.2$ to 692.8$)$ & .75 & 456.1 (12.2 to 900.0$)$ & .04 \\
\hline
\end{tabular}

Abbreviations: BMI, body mass index; CI, confidence interval.

Table 4 The Top 10 Self-Reported Activities Engaged in Over a 3-Day Period by Children With and Without Asthma

\begin{tabular}{|c|c|c|c|}
\hline \multicolumn{2}{|c|}{$\begin{array}{c}\text { Asthma } \\
n=49\end{array}$} & \multicolumn{2}{|c|}{$\begin{array}{c}\text { No asthma } \\
n=65\end{array}$} \\
\hline Activity & Percentage of time spent (\%) & Activity & Percentage of time spent (\%) \\
\hline Sleeping & 25.6 & Sleeping & 24.6 \\
\hline Watching television/movie & 16.2 & Watching television/movie & 15.4 \\
\hline Eating & 8.0 & Eating & 8.3 \\
\hline Studying/doing homework & 6.4 & Studying/doing homework & 8.0 \\
\hline Writing/taking notes in class & 6.5 & Writing/taking notes in class & 5.4 \\
\hline Internet/video games & 5.4 & Internet/video games & 5.4 \\
\hline Walking & 5.3 & Walking & 4.6 \\
\hline Dressing/getting ready & 3.7 & Dressing/getting ready & 3.4 \\
\hline Lying down & 2.0 & Riding the bus/train/car & 2.7 \\
\hline Riding the bus/train/car & 1.8 & Simply sitting & 1.8 \\
\hline
\end{tabular}

during recess as compared with boys. There is also evidence from longitudinal studies that the disparity in physical activity levels worsens as children become adolescents, with girls' activity declining at a faster rate than boys' as they age. ${ }^{27,28}$ Forthofer et $\mathrm{al}^{29}$ showed that the factors most protective against physical activity decline during this transition to adolescence among both genders were sport and physical activity-related class participation, parent-reported support for physical activity, and neighborhood resources. However, they also found that children's self-efficacy and parents' leisure-time physical activity were more important among girls as compared with boys. ${ }^{29}$

In stratified analyses by sex, we observed a significant positive association between mean daily steps and SES score among girls but not boys (Table 4). One potential explanation for this result is that girls may be more discouraged by family members or less comfortable than boys engaging in outside play if they live in unsafe neighborhoods. This phenomenon has been observed in other studies. $^{30-32}$ Furthermore, it is possible that higher income families may be able to access activites that require greater financial resources, such as dance, which girls may be more likely to engage in. The results of our research and other studies, therefore, highlight the importance of developing strategies that acknowledge and address the social and environmental factors that make girls more vulnerable to physical inactivity. ${ }^{33}$ In the case of Peru, an understanding of the role that gender norms, child self-efficacy, and resources play in physical activity outcomes among children merits further qualitative and longitudinal investigation.

Children with asthma were less active than those without asthma, although this difference did not reach statistical significance. Given the moderate effect size ( 1000 steps per day), it is possible that this association may have reached statistical significance with a larger sample size. Furthermore, in stratified analyses by sex, boys with current asthma took over 2000 fewer steps than boys without asthma, with this difference approaching statistical significance. One possible explanation for this difference may be that, because boys are more physically active overall than girls, asthma symptoms may have a greater impact on their activity levels than for girls, who are generally more sedentary. Studies of the relationship between asthma and physical activity have shown conflicting results. In a longitudinal study of 147 children aged 5-12 years of age in Baltimore, MD, Nnodum et $\mathrm{al}^{34}$ found a significant association between physical activity, as measured by the physical activity questionnaire, and an increased frequency of asthma symptoms. These results suggest that children may be more bothered by their asthma when engaged in higher levels of physical activity. Furthermore, Holderness et $\mathrm{al}^{35}$ found that, among the 324 children studied, there was a significant correlation between the level of asthma control and physical activity, with children having uncontrolled asthma reporting less physical activity than their peers who had mild asthma or no asthma. However, Matsunaga et $\mathrm{al}^{36}$ found no such correlation in a population of 100 children studied. A meta-analysis of 8 cross-sectional and 1 longitudinal study using data from accelerometry demonstrated no significant difference in physical activity levels between children with and without asthma; however, our study used pedometers as opposed to accelerometers, the former of which do not measure exercise intensity. ${ }^{37}$ Therefore, our study was unable to probe this hypothesis further.

Although not statistically significant, the trend toward higher physical activity levels in children without asthma could indicate a propensity for the latter group to engage in fewer strenuous 
activities. Indeed, despite the likely benefits of exercise, children with asthma, especially those with severe disease, are often less likely to participate in physical activity for reasons such as parental fears or children's lack of confidence in their own physical abilities because of their asthma. ${ }^{38}$ Further qualitative research into the perceptions of the impact of physical activity on disease and quality of life in this population would help elucidate potential barriers to physical activity promotion among this population.

There are several strengths to this study. We are one of the first groups to characterize the daily activity patterns of children living in Peru or other South American countries. We also employed both quantitative and qualitative methods to assess physical activity, allowing for a triangulation of our results and greater granularity in terms of the specific daily activities engaged in by children in these communities.

This study also has important limitations. First, due to the cross-sectional nature of this study, we are unable to determine temporality or causality of the relationship between risk factors and physical activity levels. The statistical power to detect a difference in physical activity levels by different risk factors was also limited by the small sample size. Being both questionnaire-based and retrospective, the 3DPAR is susceptible to recall bias. However, the 3DPAR uses a relatively short recall window of 3 days, which helps minimize the impact of this bias. ${ }^{17} \mathrm{We}$ also used pedometers to provide a quantitative complement to the qualitative physical activity information collected by the 3DPAR. ${ }^{18}$ The use of pedometers did not allow us to determine the intensity of the physical activity or calculate metabolic equivalents. Furthermore, we did not collect data on the days of the study on which the children attended school, which could affect their physical activity levels. We also did not collect data on asthma severity, thus leaving us unable to evaluate whether this variable would be correlated with a change in physical activity levels. Lastly, there is potential for differential misclassification bias resulting from girls being engaged in activities that make it more difficult to wear pedometers, such as dance.

Given the importance of physical activity for preventing future disease and ensuring well-being throughout the lifespan, our data demonstrate the need for strategies and policies to promote physical activity and education among youth in urban and peri-urban communities of Peru. Our data do not indicate that children with asthma should be targeted specifically in physical education strategies; however, future qualitative studies into perceptions regarding the dangers of physical activity for children with asthma may be warranted, given the trend toward greater inactivity among these children. Strategies and policies for youth physical activity should take into account the social, cultural, and environmental factors that drive disparities in physical activity between certain groups, particularly gender-based differences.

\section{Acknowledgements}

The authors gratefully acknowledge the study participants and their families for their cooperation and participation. This project was funded by a grant from the National Institute of Environmental Health Sciences, National Institutes of Health (R01ES018845 and R01ES018845-S1), and Biomedical Research, Nemours Children's Health System. S.L.P. was supported by a grant from the Fogarty International Center; Office of AIDS Research; National Cancer Center; National Heart, Blood, and Lung Institute; and the NIH Office of Research for Women's Health through the Fogarty Global Health Fellows Program Consortium comprised of the University of North Carolina, Johns Hopkins University, Morehouse
School of Medicine, and Tulane University (5R25TW009340). S.L.P. was also supported by a Mentored Research Scientist Development Award [1K01HL140048] from the National Heart, Lung, and Blood Institute, National Institutes of Health.

\section{References}

1. Physical Activity. World Health Organization. 2018. https://www. who.int/news-room/fact-sheets/detail/physical-activity

2. Sport and the Sustainable Development Goals. United Nations Office on Sport for Development and Peace. 2019. https://www.un. org/sport/sites/www.un.org.sport/files/ckfiles/files/Sport_for_SDGs_ finalversion9.pdf

3. Lucas SR, Platts-Mills TAE. Physical activity and exercise in asthma: relevance to etiology and treatment. J Allerg Clin Immunol. 2005; 116(2):298. doi:10.1016/j.jaci.2005.05.039

4. Rota AP, Bacharier LB, Jaffee K, et al. Screen time engagement is increased in urban children with asthma. Clin Pediatr. 2017;56(11): 1048-1053. doi:10.1177/0009922817698801

5. Pianosi PT, Davis HS. Determinants of physical fitness in children with asthma. Pediatrics. 2012;113(3):e225-e229. doi:10.1542/peds. 113.3.e225

6. Checkley W, Pollard SL, Siddharthan T, et al. Managing threats to respiratory health in urban slums. Lancet Respir Med. 2016;4(11): 852-854. PubMed ID: 27760724 doi:10.1016/S2213-2600(16) 30245-4

7. Ford ES. The epidemiology of obesity and asthma. J Allerg Clin Immunol. 2005;115(5):897-909. doi:10.1016/j.jaci.2004.11.050

8. Gennuso J, Epstein LH, Paluch RA, Cerny F. The relationship between asthma and obesity in urban minority children and adolescents. Arch Pediatr Adolesc Med. 1998;152(12):1197-1200. PubMed ID: 9856429 doi:10.1001/archpedi.152.12.1197

9. Fedele DA, Janicke DM, Lim CS, Abu-Hasan M. An examination of comorbid asthma and obesity: assessing differences in physical activity, sleep duration, health-related quality of life, and parental distress. J Asthma. 2014;51(3):275-281. PubMed ID: 24320738 doi:10.3109/02770903.2013.873807

10. Urban Population. The World Bank. 2018. https://data.worldbank. org/indicator/sp.urb.totl.in.zs

11. Robinson CL, Baumann LM, Romero K, et al. Effect of urbanization on asthma, allergy, and airways inflammation in a developing country setting. Thorax. 2011;66(12):1051-1057. PubMed ID: 21730351 doi:10.1136/thx.2011.158956

12. Hansel NN, Romero KM, Pollard SL, et al. Ambient air pollution and variation in multiple domains of asthma morbidity among Peruvian children. Ann Am Thorac Soc. 2019;16(3):348-355. PubMed ID: 30365919

13. Pollard SL, Lima JJ, Mougey E, et al. Associations between serum $25(\mathrm{OH}) \mathrm{D}$ concentrations and prevalent asthma among children living in communities with differing levels of urbanization. Asthma Res Pract. 2017;3(1):5. doi:10.1186/s40733-017-0033-2

14. Weston AT, Petosa R, Pate RR. Validation of an instrument for measurement of physical activity in youth. Med Sci Sports Exerc. 1997;29(1):138-143. PubMed ID: 9000167 doi:10.1097/00005768199701000-00020

15. Pate RR, Ross R, Dowda M, Trost SG, Sirard J. Validation of a threeday physical activity recall instrument in female youth. Pediatr Exerc Sci. 2003;15(3):257-265. doi:10.1123/pes.15.3.257

16. Ainsworth BE, Haskell WL, Whitt MC, et al. Compendium of physical activities: an update of activity codes and MET intensities. Med Sci Sports Exerc. 2000;32(9):S498-S516. PubMed ID: 10993420 doi:10.1097/00005768-200009001-00009 
17. Sallis JF, Saelens BE. Assessment of physical activity by self-report: status, limitations, and future directions. Res Q Exerc Sport. 2000; 71(suppl 2):1-14. doi:10.1080/02701367.2000.11082780

18. Tudor-Locke C, Williams JE, Reis JR, Pluto D. Utility of pedometers for assessing physical activity. Sports Med. 2002;32(12):795-808. PubMed ID: 12238942 doi:10.2165/00007256-200232120-00004

19. Tudor-Locke C, Craig CL, Beets MW, et al. How many steps/day are enough for children and adolescents? Int J Behav Nutr Phys Act. 2011;8(1):78. PubMed ID: 21798014 doi:10.1186/1479-5868-8-78

20. Beets MW, Bornstein D, Dowda M, Pate R. Compliance with national guidelines for physical activity in US preschoolers: measurement and interpretation. Pediatr. 2011;127(4):658-664. doi:10.1542/peds. 2010-2021

21. Rey-Lopez JP, Vicente-Rodriguez G, Biosca M, Moreno LA. Sedentary behavior and obesity development in children and adolescents. Nutr Metab Cardiovasc Dis. 2008;18(3):242-251. PubMed ID: 18083016

22. Gomez JE, Johnson BA, Selva M, Sallis JF. Violent crime and outdoor physical activity among inner-city youth. Prev Med. 2004;39(5):876881. PubMed ID: 15475019 doi:10.1016/j.ypmed.2004.03.019

23. Telford RM, Telford RD, Olive LS, Cochrane T, Davey R. Why are girls less physically active than boys? Findings from the LOOK Longitudinal Study. PLoS One. 2016;11(3):e0150041. PubMed ID: 26960199 doi:10.1371/journal.pone.0150041

24. Azevedo MR, Araújo CLP, Reichert FF, Siqueira FV, da Silva MC, Hallal PC. Gender differences in leisure-time physical activity. Int $J$ Public Health. 2007;52(1):8-15. PubMed ID: 17966815 doi:10. 1007/s00038-006-5062-1

25. Ishii K, Shibata A, Adachi M, Nonoue K, Oka K. Gender and grade differences in objectively measured physical activity and sedentary behavior patterns among Japanese children and adolescents: a crosssectional study. BMC Public Health. 2015;15(1):1254. PubMed ID: 26679503 doi:10.1186/s12889-015-2607-3

26. Baquet G, Ridgers ND, Blaes A, Aucouturier J, Van Praagh E, Berthoin S. Objectively assessed recess physical activity in girls and boys from high and low socioeconomic backgrounds. BMC Public Health. 2014;14(1):192. PubMed ID: 24559254 doi:10.1186/14712458-14-192

27. Marques A, Carreiro da Costa F. Levels of physical activity of urban adolescents according to age and gender. Int J Sports Sci. 2013;3(1): 23-27.

28. Butt J, Weinberg R, Breckon JD, Claytor R. Adolescent physical activity participation and motivational determinants across gender, age, and race. J Phys Act Health. 2011;8(8):1074-1083. PubMed ID: 22039125 doi:10.1123/jpah.8.8.1074

29. Forthofer M, Dowda M, O'Neill JR, et al. Effect of child gender and psychosocial factors on physical activity from fifth to sixth grade. $J$ Phys Act Health. 2017;14(12):953-958. PubMed ID: 28682693 doi:10.1123/jpah.2016-0487

30. McTigue KM, Cohen ED, Moore CG, Hipwell AE, Loeber R, Kuller LH. Urban neighborhood features and longitudinal weight development in girls. Am J Prev Med. 2015;49(6):902-911. PubMed ID: 26169131 doi:10.1016/j.amepre.2015.05.021

31. Voorhees CC, Catellier DJ, Ashwood JS, et al. Neighborhood socioeconomic status and non school physical activity and body mass index in girls. J Phys Act Health. 2009;6(6):731-740. PubMed ID: 20101916 doi:10.1123/jpah.6.6.731

32. Rupp K, Ross SET, Gary-Webb TL, Akiva T, Jakicic JM. Household support for physical activity in adolescent girls living in primarily low socioeconomic status neighborhoods. Int J Exerc Sci. 2019;12(5): 811-824. PubMed ID: 31156756

33. Solmon MA. Physical education, sports, and gender in schools. Adv Child Dev Behav. 2014;47:117-150. doi:10.1016/bs.acdb. 2014.04.006

34. Nnodum BN, McCormack MC, Putcha N, et al. Impact of physical activity on reporting of childhood asthma symptoms. Lung. 2017;195(6): 693-698. PubMed ID: 28914352 doi:10.1007/s00408-017-0049-7

35. Holderness H, Chin N, Ossip DJ, Fagnano M, Reznik M, Halterman JS. Physical activity, restrictions in activity, and body mass index among urban children with persistent asthma. Ann Allergy Asthma Immunol. 2017;118(4):433-438. PubMed ID: 28268134 doi:10. 1016/j.anai.2017.01.014

36. Matsunaga NY, Oliveira MS, Morcillo AE, Ribeiro JD, Ribeiro MAGO, Toro AADC. Physical activity and asthma control level in children and adolescents. Respirology. 2017;22(8):1643-1648. PubMed ID: 28612960.10.1111/resp.13093

37. Cassim R, Koplin JJ, Dharmage SC, et al. The difference in amount of physical activity performed by children with and without asthma: a systematic review and meta-analysis. J Asthma. 2016;53(9): 882-892. PubMed ID: 27144654 doi:10.1080/02770903.2016. 1175474

38. Jago R, Searle A, Henderson AJ, et al. Designing a physical activity intervention for children with asthma: a qualitative study of the views of healthcare professionals, parents and children with asthma. BMJ Open. 2017;7(3):e014020. PubMed ID: 28341689 doi:10.1136/ bmjopen-2016-014020 